National Academy of Sciences, it does excellently; against the equally distinguished members of the National Academy of Engineering, not so well but still respectably.

How it copes with the newer recruits to the life of science is yet another question. The fourteenth edition added 13,000 new names to the roster; the fifteenth only 7,500. According to the editors, there were fewer nominations this time, and only 20 per cent of the forms sent out to the nominees were returned, a figure that seems astonishingly low. All those returned were reviewed for acceptability, 75 per cent of them being considered suitable for mention in the new edition.

A random test of the effectiveness of updating suggests that it has been spotty. Some very recent moves have been caught by the editors, others missed. David Hamburg, who in October 1980 left the presidency of the Institute of Medicine in Washington DC to join the Harvard faculty, is still listed at the Institute, but oddly with the Harvard address. By the time the fifteenth edition reaches most library shelves, Dr Hamburg will already have left Harvard to become president of the Carnegie Corporation of New York. Such are the woes of the editors of AMWS.

Howard J. Lewis, based in Washington DC, is a writer on science policy.

\section{EGG and malignancy}

\section{Peter Alexander}

The Biology of Tumour Malignancy. By G.V. Sherbet. Pp.255. ISBN 0-12639880-1. (Academic: 1982.) £19.20, $\$ 36$.

UNDERSTANDING of the nature of malignant transformation at the molecular level is advancing at a pace which is truly phenomenal. Important new findings appear almost every week. The outline of a general theory is clearly emerging and this seems to account adequately for many of the findings in the field of carcinogenesis. The hypothesis that the malignant phenotype arises from a quantitative and not a qualitative change in the genome, such that

one or more of a group of diverse normal genes - the oncogenes - are expressed to a greater extent, is gaining support all the time.

So far so good, but cancer as a disease has to be considered in the context of the whole organism. The full potential of new approaches to both treatment and prevention, which derive from the currently acquired knowledge of the sub-cellular lesions responsible for cancer, is unlikely to be realized without a better understanding of the role of the host which can determine the pattern and rate of growth of cells that have been transformed. Both seed and soil need to be considered.

Quite excellent monographs dealing with the interaction of host and tumour have been written by Rupert Willis and Leslie Foulds, and these are still essential reading for the cancer researcher. But they are now dated and an up-to-date treatise would be immensely valuable. The slim book of Dr Sherbet does not, unfortunately, fill this role as its principal objective is to describe a test for assaying the malignancy of a tumour from a biopsy specimen by a procedure developed by the author and called "epigenetic grading" (EGG).

In the test, cells from the tumour are injected into embryonic tissue of the chicken - the 18-hour old blastoderm cultured together for some 18 hours and then examined histologically. According to the author, the morphological response of the embryonic tissue to the tumour cells correlates with the malignancy (here defined as invasiveness and capacity to metastasize) of the tumour. The data to substantiate the claim made for EGG, are, however, extremely thin and the scientific basis of the technique remains imprecise. This topic may be of interest as a research project but has not advanced sufficiently to justify the writing of a monograph.

The first third of the book provides a thoughtful, well-informed if brief and therefore selective review of the biology of metastasis; cell detachment, invasion, distant seeding and the part of the immune system in these processes are considered in an orthodox frame. While this chapter is a useful introduction to the topic, it is not enough to warrant the publication and purchase of the entire book.

Peter Alexander, formerly at the Institute of Cancer Research, is now in the CRC Medical Oncology Unit at the General Hospital, Southampton.

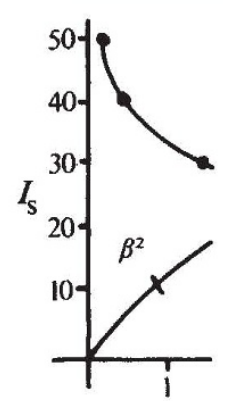

\section{Biomodels}

A model in its elegance Is better than reality Its graphical simplicity Denotes a rare intelligence.

The simple graph incites the wrath Of field men who, half undressed, Go rushing out to start a test Which culminates in aftermath.
"Biomodels" is taken from John M. Burns' collection of poems, BioGraffiti: A Natural Selection, which has recently been re-issued in paperback by W.W. Norton. Price of the new edition is $\$ 3.95, £ 2.95$.

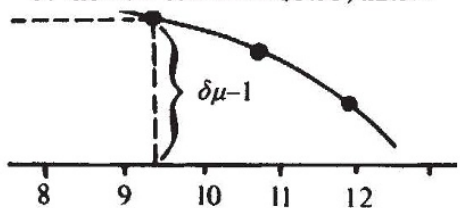

No direct path from genes to phenotype

\section{Lindon J. Eaves}

Biometrical Genetics: The Study of Continuous Variation, 3rd Edn. By Kenneth Mather and John L. Jinks. Pp.396. ISBN 0-412-22890-4. (Chapman \& Hall: 1982.) $£ 22.50, \$ 49.95$.

ABout 80 years ago, Karl Pearson browbeat William Bateson and his fellow Mendelians for their mathematical incompetence. The image of quantitative genetics has never recovered from this early conflict between mathematics and biology. Many geneticists still view biometrical genetics as an arcane pursuit, one that has been eclipsed by developments in molecular genetics. Mather and Jinks, founders of what many now describe as the "Birmingham school" of biometrical genetics, are almost unique in being geneticists, rather than mathematicians, who have applied their talent to understanding the origin and significance of continuous variation.

Readers of this new edition of Mather and Jinks should be left in no doubt that biometrical genetics addresses fundamental biological issues that are left untouched by the molecular approach. Variation in continuous traits is seldom entirely genetic and rarely due to just one or two loci. Furthermore, genes often do not contribute additively to the phenotype but may interact with one another and with the environment, and may even create the environment in which they are expressed. Theories of the origin and evolutionary dynamics of variation will fail if they are developed in ignorance of the rules relating effects.of individual genes at the molecular and biochemical level to the complex aspects of the phenotype on which natural and artificial selection are based. This perspective is essential to the scientific understanding of variation within species.

The book describes how the statistics derived from breeding studies can be interpreted in genetical terms and how studies can be designed to enhance the power of a genetical analysis. The treatment of genotype-environment interaction, for example, goes far beyond a mere statistical description of interaction and into the analysis of gene action affecting sensitivity to the environment. Mather and Jinks offer breeding programmes to resolve the additive, dominant and epistatic components of gene action and the effects of linkage and maternal inheritance; in particular, their discussion of the "effective factor" should lend caution to the current quest for single loci of large effect. They present data showing that estimates of the number of genes affecting a quantitative trait are directly proportional to the industry and ingenuity of the investigator.

Critics have commented that Mather and 